\title{
Simultaneous Improvement of the Electric Conductive and Mechanical Properties of Nanostructured Aluminum Alloy
}

Emerson Prazeres ( $\square$ eng.emersonrodrigues@gmail.com )

Programa de Pós-Graduação em Engenharia de Recursos Naturais da Amazônia (PRODERNA/ITEC), Federal University of Para

\section{Cristian Loayza}

Programa de Pós-Graduação em Engenharia de Recursos Naturais da Amazônia (PRODERNA/ITEC), Federal University of Para

\section{Vinicius Reis}

Federal University of Para

\section{Victor Melo}

Federal University of Para

\section{José Quaresma}

Federal University of Para

\section{Marcos Reis}

Programa de Pós-Graduação em Engenharia de Recursos Naturais da Amazônia (PRODERNA/ITEC), Federal University of Para José Silva

Programa de Pós-Graduação em Engenharia de Recursos Naturais da Amazônia (PRODERNA/ITEC), Federal University of Para

\section{Eduardo Braga}

Programa de Pós-Graduação em Engenharia de Recursos Naturais da Amazônia (PRODERNA/ITEC), Federal University of Para

\section{Research Article}

Keywords: Aluminum nanocomposites, multiwalled carbon nanotubes, nanostructured stainless-steel powder

Posted Date: November 17th, 2021

DOI: https://doi.org/10.21203/rs.3.rs-1087558/v1 
License: (c) (i) This work is licensed under a Creative Commons Attribution 4.0 International License. Read Full License 


\title{
Simultaneous Improvement of the Electric Conductive and Mechanical Properties of Nanostructured Aluminum Alloy
}

\author{
Emerson Prazeres ${ }^{1, *}$, Cristian Loayza ${ }^{1,+}$, Vinicius Reis ${ }^{2}$, Victor Melo $^{2}$, José Quaresma $^{3,+}$, \\ Marcos Reis ${ }^{1,5,+}$, José Silva ${ }^{1,+}$, and Eduardo Braga ${ }^{1,4+}$ \\ ${ }^{1}$ Programa de Pós-Graduação em Engenharia de Recursos Naturais da Amazônia (PRODERNA/ITEC), Federal \\ University of Pará, Belém PA, 66075-110, Brazil \\ ${ }^{4}$ Programa de Pós-graduação em Engenharia Mecânica (PPGEM/UFPA), Federal University of Pará, Belém PA, \\ 66075-110, Brazil \\ ${ }^{5}$ Faculdade de Ciências Exatas e Tecnologia, Federal University of Pará, Abaetetuba PA, 68440-000, Brazil \\ ${ }^{2}$ Faculdade de Engenharia Mecânica (FEM/ITEC), Federal University of Pará, Belém PA 66075-110, Brazil \\ ${ }^{3}$ Programa de Pós-graduação em Engenharia Industrial (PPGEI/UFPA), Federal University of Pará, Belém PA, \\ 66075-110, Brazil \\ *eng.emersonrodrigues@gmail.com \\ +these authors contributed equally to this work
}

\section{ABSTRACT}

Aluminum nanocomposites demonstrate improvements in the mechanical properties, as well as in thermal and electric conductivity. The incorporation of multiwalled carbon nanotubes (MWCNT) in the aluminum matrix, using conventional melting methods, is a long-standing issue. In this paper, Aluminum nanocomposites were fabricated via conventional casting method, using a nanostructured stainless-steel (SS) powder. Carbon nanotubes were treatment treated with hydrogen peroxide, allowed which led to an attachment with to the metal matrix particles. In this sense, The the SS powder, added as an element alloy, refinement refined the grains, and the MWCNT providedled the electric conductive to a better performance. Given this, the best alloy analyzed presented an approximate $10 \%$ increase in all of its characterized properties, that is, therefore presenting a microhardness of $48 \mathrm{HV}$, a Ultimate Tensile Stress of $183 \mathrm{Mpa}$, and and an electrical conductivity of $67 \%$ of IACS..

\section{Introduction}

Pure aluminum had a great level of electric conductivity ( 61\% IACS), however, their its ultimate tensile strength is low ( 170 $\mathrm{MPa}$ ), which encouraged a reinforcement using a steel wire rope - an impractical, expensive, and prolonged process. Elements alloys increment the mechanical properties but lessen the EC, making it unfeasible. Nanotechnology could provide solutions to this problem, e. g., carbon nanotubes (CNT) have outstanding mechanical and physical properties as low density, tensile strength ( $110 \mathrm{GPa})$, yield module $(0.6-5.5 \mathrm{MPa})$, thermal $\left(6000 \mathrm{~W} \mathrm{~m} \mathrm{~K}^{1} \mathrm{~K}^{-1}\right.$-SCNT- and $3000 \mathrm{~W} \mathrm{~m} \mathrm{~K}^{1} \mathrm{~K}^{-1}$-MWCNT) and electric conductivity (107 to $\left.109 \mathrm{~A} \mathrm{~cm}^{-2}\right)^{1,2}$. However, its production in a large scale is already is restrictive due its high cost pf almost $1000 \mathrm{USD} / \mathrm{kg}$. This price is estimated to drop in the next years, making feasible the use of CNT to substitute the conventional materials ${ }^{3}$.

Currently, they are used as reinforcement of nanocomposites with metal matrices such as Nickel ${ }^{4,5}, \mathrm{Cooper}^{6}, \mathrm{Iron}^{7-10}$ and, $^{7}$ mainly, Aluminum ${ }^{11-14}$, due to their features of a nanofiber ideal ${ }^{15,16}$. However, the difficulty in obtaining a uniform distribution and the CNTs agglomerations (clusters) in the matrix caused by Van der Waals forces, in addition to the density disparity between MWCNTs and aluminum alloy, are long-standing issues in the fabrication of metal composites ${ }^{7,8,17}$.

Aluminum nanocomposites (ANC) are very promising; there are many techniques and researches involvinge the inclusion of CNT in aluminum Metal Matrix (MM), e.g., powder metallurgy ${ }^{18,19}$, spark plasma sintering ${ }^{20}$, hot spark ${ }^{21}$, mechanical allowing ${ }^{9,22}$, and stirring casting, i. a., but almost all the processes are very expensive and complex. In addition, no avoid agglomeration nor reach structural integrity, and do not have a proper bonding with the $\mathrm{MM}^{23}$.

The stirring casting is quite widespread given the possibility of a greater uniform dispersion of the reinforcement material in the matrix, as well as a lower working temperature, which limits uncontrolled chemical reactions and the appearance of carbides due to high temperatures ${ }^{24}$, but the process is prolonged and more expensive than agitation casting ${ }^{17,25}$. It is necessary to incorporate CNT with conventional casting ${ }^{26}$, even though high temperatures can destroy the surface integrity of CNTs. This 
paper presents a methodology that allowed the incorporation of CNTs via conventional casting, increasing both the mechanical properties and electric conductivity.

\section{Results}

Figure 1 shows the scheme of the casting and solidification process in the cylindrical metallic mold. For the $0.05 \mathrm{C}$ alloy, only carbon nanotubes $(0.05 \mathrm{wt} . \%)$ were inserted into the liquid metal, and then the mold was poured; it was expected that the carbon nanotube agglomeration would occur, and as the density of CNT is lesser than that of aluminum, they tend to clump on top of the liquid metal ${ }^{17,27}$. Posteriorly, the CNT was deposited in the mold alongside the first portion of the cast aluminum, and, as the solidification occurs quickly, there is not enough time for the CNT to move upwards in the mold, because the first part of the deposited metal, once solidified, holds the nanotubes at the bottom of the produced ingot ${ }^{28,29}$. The $2 \mathrm{SS} 0.1 \mathrm{C}$ alloy $(2$ wt.\% SS-0.1 wt.\% CNT) was poured into the mold, as shown in Fig. 1. It was noted that part of the mixture disperses in the liquid metal, however, it is expected that the excess mixture will agglomerate at the bottom of the crucible, due to the excess nanostructured powder having a higher density than liquid aluminum ${ }^{30}$. This behavior resulted in a little amount of the mixture of metallic powder and nanotubes being dispersed in the molten metal, but almost all the elements alloys were at the bottom of the crucible, reducing the reinforcement effect and deteriorating the properties of the alloy. This decantation could occur due to the limit of solubility of the alloy elements, combined with the low temperature and the melting time ${ }^{31}$. For the $1 \mathrm{SS} 0.05 \mathrm{C}$ alloy ( $1 \mathrm{wt} . \% \mathrm{SS}-0.05 \mathrm{wt} \%$ CNT), the reinforcement tends to disperse in the matrix when the casting is performed, with a tendency to remain dispersed in the mold, generating the best reinforcement mechanism with an excellent performance ${ }^{30}$.
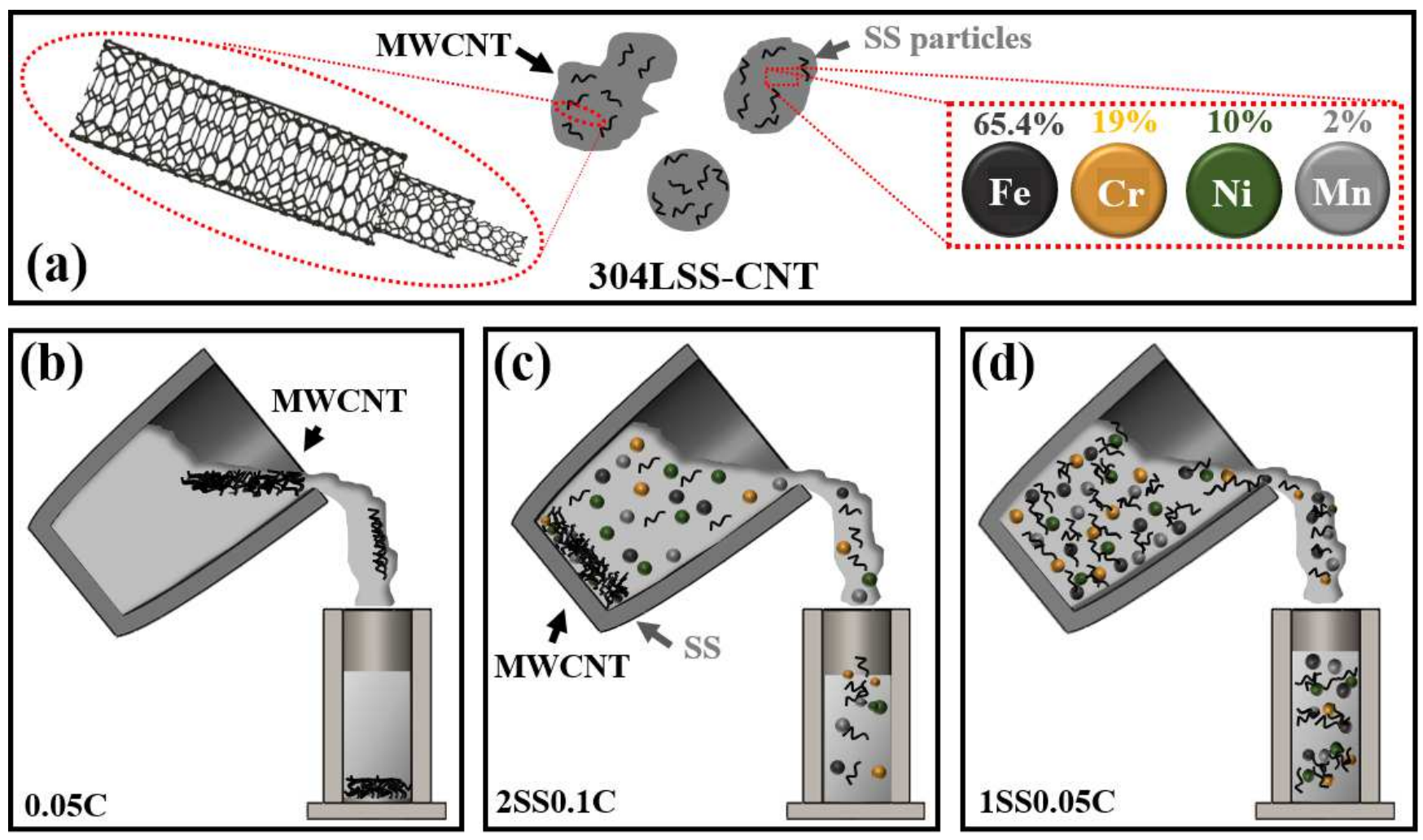

Figure 1. (a) Schematic of the nanostructured powder of 304LSS-5wt.\%CNT, appreciating the carbon nanotubes and the stainless-steel particles with their chemical composition. (b) The schematic casting for the aluminum alloy with 0.05 wt.\% CNT (0.05C), (c) 2 wt.\% SS-0.1wt.\% CNT (2SS0.1C), and (d) 1 wt.\% SS-0.05wt.\% CNT (1SS0.05C), as observed the various mechanisms of nanotubes addition involved in every each.

The alloys obtained were microstructurally characterized using SEM with EDS; the electric conductivity was measured both electrically and mechanically through the microhardness test and the tensile strength test. Fig. 2 shows the SEM micrographs and EDS mapping of the Fe to the various alloys, as the Fig. 2a shows the typical microstructure of the pure aluminum with low Fe impurity, as shows in Fig. $2 \mathrm{f}^{32}$. The addition of $0.05 \mathrm{wt} . \%$ CNT (Fig. 2b and Fig.2g) modified this microstructure, avoiding a segregation of iron to the contou of the dendrites, however that when $1 \mathrm{wt}$. $\%$ SS was incorporated there was a higher precipitation of the alloy's elements into the solute ${ }^{17,33}$. 
The addition of the nanostructured powder (304LSS-CNT) with 1wt.\%SS-0.05wt.\%CNT ( Fig. 2d and Fig. 2e) changed the aluminum's microstructures, creating elongated grains, with a low segregation of the Fe and of the other elements in the dendrite's limits ${ }^{33}$. This behavior could be associated with the combination of a decreasing of the grain size by effect to the stainless-steel particles and a uniform distribution of the carbon nanotubes in the MM, which avoids a bigger movement of the atoms by the effect of the pine with mainly $\mathrm{Cr}$ and $\mathrm{Ni}$ whose carbon affinity is great ${ }^{10,17}$. When the percentage of SS increase to $2 \mathrm{wt} . \%$ (e, j), along $0.1 \mathrm{wt} . \% \mathrm{CNT}$, the microstructure was remarkably altered but no segregation was observed, as the temperature of the liquid aluminum was not enough to melt all the SS particles, which produced a deterioration of the properties of this sample ${ }^{33}$.
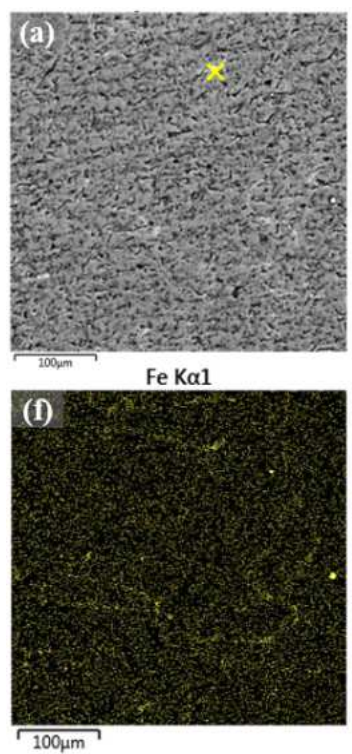
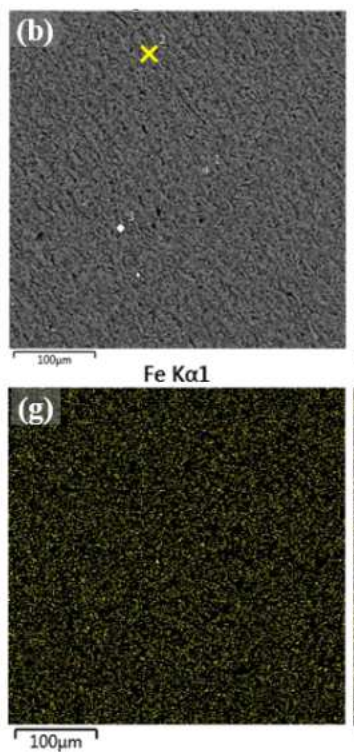
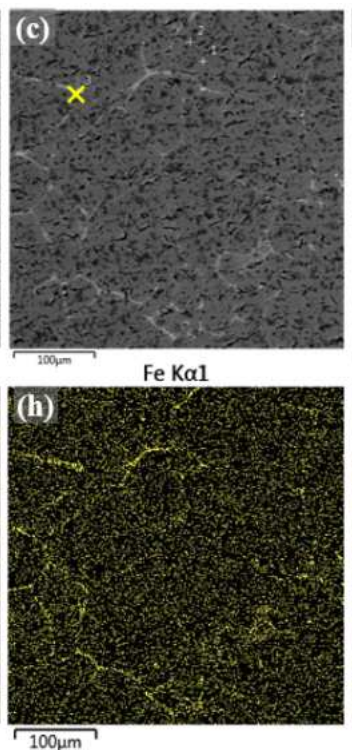
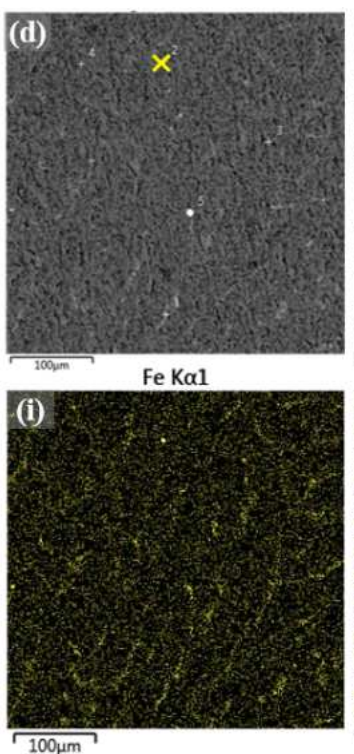
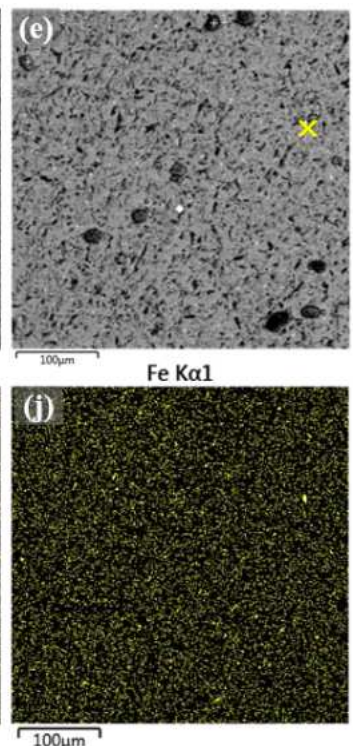

Figure 2. SEM micrographs (top) and EDS mapping (bottom) of the iron (Fe) element alloy for the various samples. (a, f) Pure Al [AlEC], (b, g) Al-0.05wt.\%CNT [0.05C], (c, h) Al-1wt.\%SS [1SS], (d, i) Al-1wt.\%SS-0.05wt.\%CNT [1SS0.05C], and (e, j) Al-2wt.\%-0.1wt.\%CNT [2SS0.1C].

Raman spectroscopy analyses showed that the Amorphous Carbon Degree (ACD) reduces with the chemical treatment (CT) with hydrogen peroxide, going from $8 \%$ for the CNT, as it was received, to $4 \%{ }^{10}$. The ID/IG rate changed from 0.95 to 0.66 , resulting in an increment of the crystallinity by effect of the treatment. For the MWCNT the ID/I $\mathrm{I}_{\text {Ginner }}$ and ID/I $\mathrm{I}_{\text {Gouter }}$ rates were 1.1 and 2.6 respectively, varying between 0.99 and 0.98 after selective oxidation, in that same order. The high values of the outermost walls rate (ID/IGouter), for the MWCNT, revealed low levels of crystalline, impurities, defectives layers, functionalization, and amorphous carbon close to the surface; indeed, the innermost walls had a low rate, indicating a good performance $8,10,13$. By applying the $\mathrm{CT}$, the rates of both walls were similar, close to one, displaying an improvement of the crystalline. There is a high redshift for the inner $\left(11 \mathrm{~cm}^{-1}\right)$ and outer $\left(26 \mathrm{~cm}^{-1}\right)$ walls, indicated by the $\mathrm{G}_{\text {inner }}$ and $\mathrm{G}_{\text {outer }}$ center position. That redshift suggested a tensile strain producing a photon softening (n-doping), as the external walls presented a higher difference suggesting a great interaction with the MM, which produces a bonding between the carbon nanoparticles and the stainless-steel particles ${ }^{8,10,13}$. This effect was confirmed by the $\Delta \mathrm{G}_{\text {position }}\left(\mathrm{G}_{\text {outer }}-\mathrm{G}_{\text {inner }}\right)$ going from $23 \mathrm{~cm}^{-1}$ (MWCNT) to $13 \mathrm{~cm}^{-1}$ (304LSS-CNT), with the low distance between the peaks indicating a high doping. All of this information was supported by Fig. 3, and can also be found as Supplemental material online in Table S1, Table S2 and Table S3. Fig. 4 exhibited the XRD patterns for the carbon nanotubes, stainless-steel particles, and the nanostructured powder. Feature peaks for each material were observed for nanotubes -C(002), C(100), and C(004)- and 304LSS - $\gamma(111), \alpha(110), \gamma(200)$, and $\gamma(220)$, as seen in Fig. 4. The nanostructured powder evidenced a reduction in the intensity of the austenitic plane (111), in part due to the superposition with $\mathrm{C}(100)$ of the carbon nanotubes, and to the high X-ray absorption capacity of the latter, while the peak $\mathrm{C}(002)$ can already is be noted in the spectrum ${ }^{9,10,34}$. All of this proves that the nanostructured powder (304LSS-CNT) was introduced efficiently in the melting aluminum to supply elements alloys such as $\mathrm{Fe}, \mathrm{Cr}, \mathrm{Ni}$, and $\mathrm{Mn}$ of the stainless-steel particles, and nanofibers (MWCNT); to improve both the mechanical properties and electric conductivity ${ }^{8,12}$. The nanostructured powder is observed in the Supplementary Fig. S8 online, as the cluster of CNT is attached to the SS particles. The structural changes by effect of the chemical treatment (CT) are exhibited in the TEM micrographs of the Supplementary Fig. S9 online, as the amorphous carbon disappeared after the CT.

The tensile properties are observed in Fig. 5, alongside the dimple rate for each alloy. The curve reveals that the 1SS0.05C 

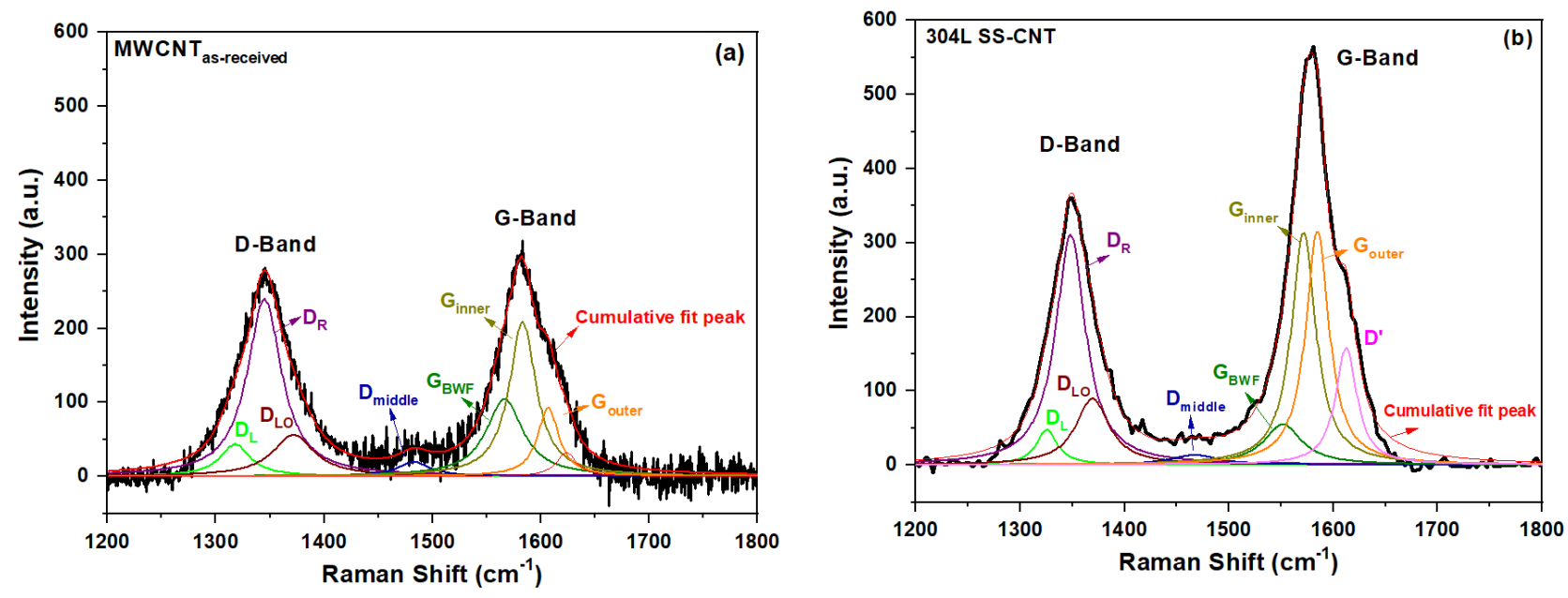

Figure 3. Raman spectroscopy deconvolved showing the $\mathrm{D}$-band and G-band and their sub-bands $\mathrm{D}_{L}, \mathrm{D}_{R}, \mathrm{D}_{L O}, \mathrm{D}_{\text {middle }}$, $\mathrm{D}$, $\mathrm{G}_{b w f}, \mathrm{G}_{\text {inner }}$ e $\mathrm{G}_{\text {outer }}$.

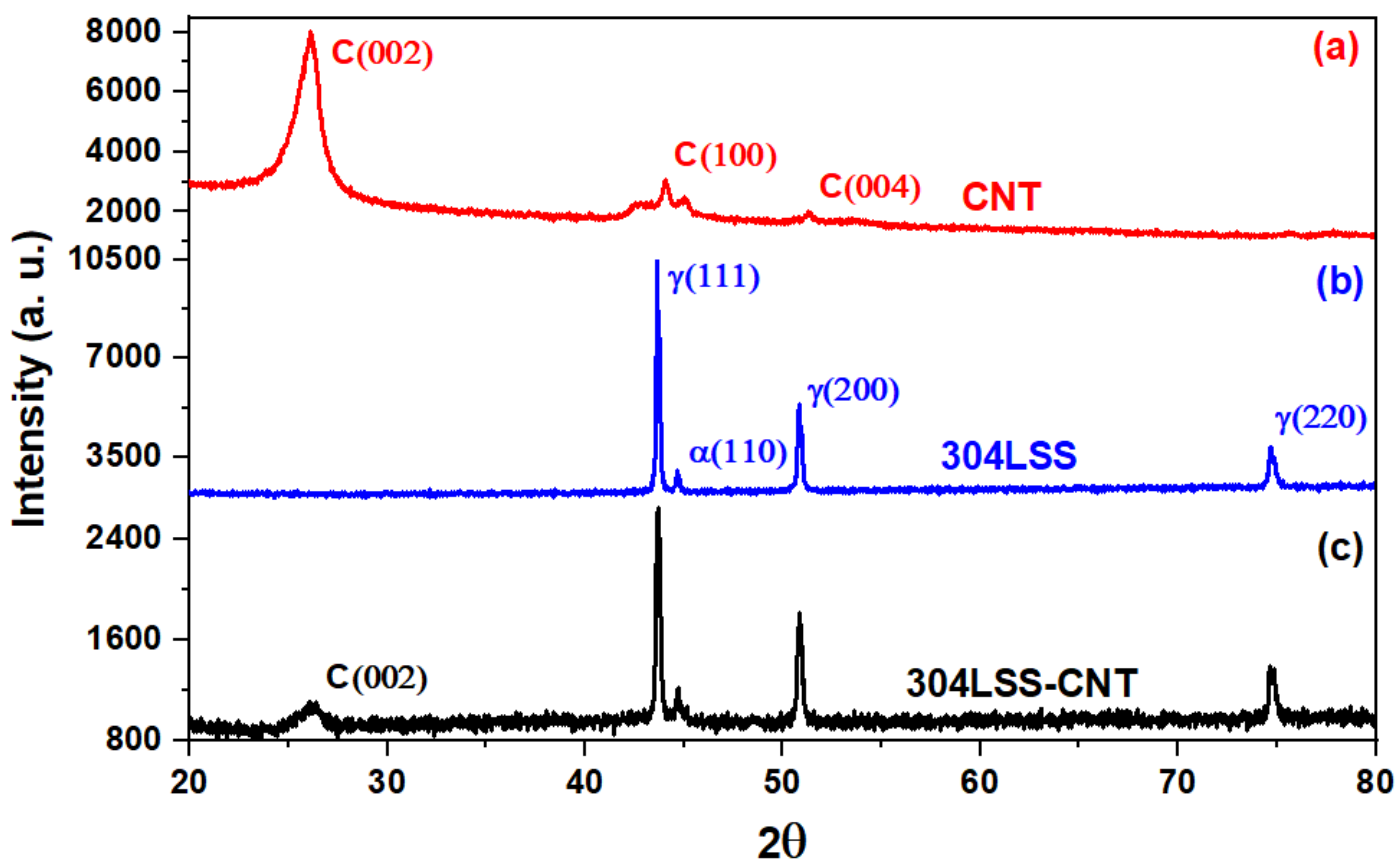

Figure 4. XRD of the (a) as received multiwalled carbon nanotubes, (b) 304L Stainless Steel particles, (c) 304LSS-CNT nanostructured powder.

had the best results of ultimate tensile strength, toughness, and strain, out of the tested alloys, due to it being combined with the improved mechanical properties resulting from the stainless steel powder and small additions of CNT that, according to the literature, ensure greater homogeneity, consequently reducing the appearance of agglomerates and the accumulation of stress ${ }^{10,30}$. The $0.05 \mathrm{C}$ alloy presented lower results than the other alloys, due to the agglomeration of nanotubes and the low density of the CNT that make them rise to the surface of the melting metal, as shown in Fig. $1 b^{8,17,30}$. CNT clusters produced an accumulation of punctual stresses, generating areas of failure and reducing the mechanical properties ${ }^{30,34}$. The dimples ratio, analyzed with the Narayanasamy et al. ${ }^{35}$ method, in which the dimples ratio farther away for one more ductile is the material, showed the superior results of the $1 \mathrm{SS} 0.05 \mathrm{C}$ alloy, justifying the reason as to why this material had a better performance of its mechanical properties. Otherwise, the $2 \mathrm{SSO} .1 \mathrm{C}$ alloy showed the most fragile rate through the analyses of the dimples, 
coinciding with the results of the tensile strength and microstructural analyses ${ }^{30,34}$.

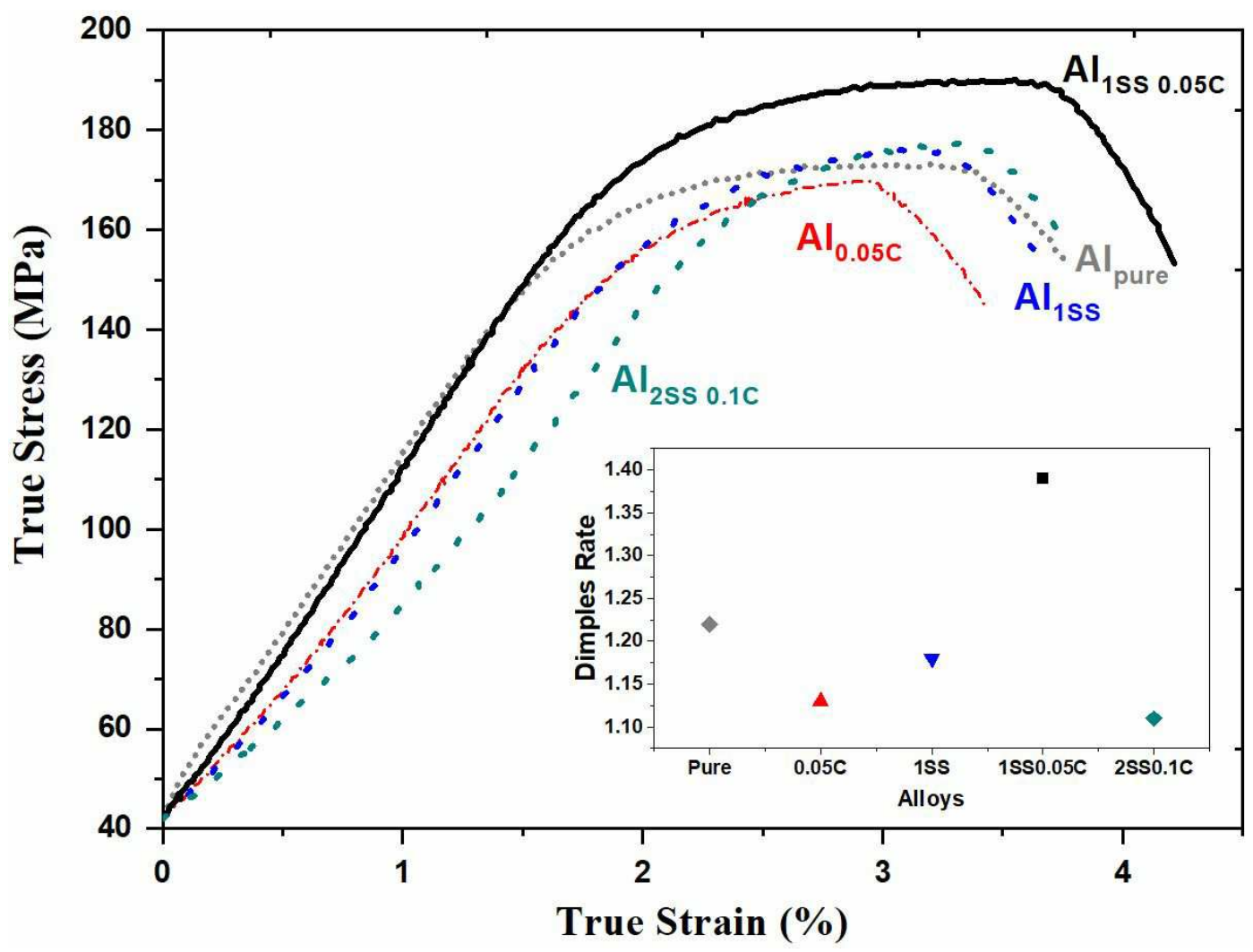

Figure 5. True Strain vs True Stress curve. Dimples ratio for the alloys.

Figure 6 shows the fractures after the traction test together with the dimples size. Low magnification (80x) presented the characteristic of grabbing the ductile materials, as is the case of aluminum alloys ${ }^{36}$.The high magnifications (1000x), displaying the dimples, it possible to obtain an average diameter through a Gaussian curve. The size of the dimples did not vary when comparing the $\mathrm{Al}_{E C}$ to the $0.05 \mathrm{C}$ sample, indicating that the incorporation of carbon nanotubes have no influence over the dimples. However, when the stainless-steel particles were added, the size decreased meaningly in the three samples. For 1 wt.\% SS samples, the dimples' size, in both samples, was almost the same ( $5.6 \mu \mathrm{m})$, while with 2 wt $\%$ of SS the reduction was more noticeable $(4.7 \mu \mathrm{m})$, with a reduction of $23 \%$ and $35 \%$, respectively. These results indicated that the SS had a higher effect over the dimples' size than the carbon nanotubes, which was confirmed by the refinement of the grains observed in the macrostructures of the Fig. 7.

Figure 7 shows the Ultimate Tensile Strength (UTS), Vickers microhardness (HV), electric conductivity (EC), and macrographs for the samples. $\mathrm{Al}_{E C}$ had the behavior described elsewhere in all of its properties, while the incorporation of 0.05wt.\% CNT decreased its performance in UTS, associated with the CNT clusters, acting as stress concentrations, and reducing its toughness ${ }^{34}$. Due to the low density of the CNT, it mainly floated and rose up to the surface, remaining only a low quantity in the matrix ${ }^{34}$. Nevertheless, the EC incremented around of $10 \%$ tobe in accordance the AlEC, indicating changes in the properties of the Al matrix. With 1wt.\% SS particles powder, the UTS slightly increases, due to the decreasing residual stresses of the alloy elements to the matrix ${ }^{12,17}$, reducing the deformation and the EC ( $\left.5 \%\right)$. The 1 SSO.05C sample had a better behavior in all of its properties (UTS, strain, toughness, microhardness, and EC), almost 10\% in each. It revealed the effect of the chemical treatment nanotubes and their capacity to be attached to the SS powder, effectively connecting the alloy elements of the SS inside the aluminum matrix, maintaning their reinforcement effect ${ }^{10,30}$. With higher quantities of SS and nanotubes, the reinforcement is compromised, the properties decreasing when compared to the $1 \mathrm{SS} 0.05 \mathrm{C}$ sample, but still already above the $\mathrm{Al}_{E C}{ }^{30}$. High quantifies of SS particles powder could not be meltied in the aluminum casting, due to low temperature and short time. The alloy $1 \mathrm{SS} 0.05 \mathrm{C}$ showed better results regarding the evaluated properties. In that sense, when compared to the literature, the electrical conductivity was higher than the commercial alloys Al6201 before and after the T81 heat treatment (48.9\% IACS, $50.6 \%$ IACS), in the condition of wire with $3.00 \mathrm{~mm}$ in diameter, but the ultimate tensile stress was lower than that obtained in the literature both in the condition before and after the T81 (261.7 MPa and 275.9 $\mathrm{MPa}^{37}$. $\mathrm{Al}_{E C}$ shows coarse equiaxial grains; $0.05 \mathrm{C}$ start to refine the central grains, suggesting that the internal heat transfer was higher in the middle of the 

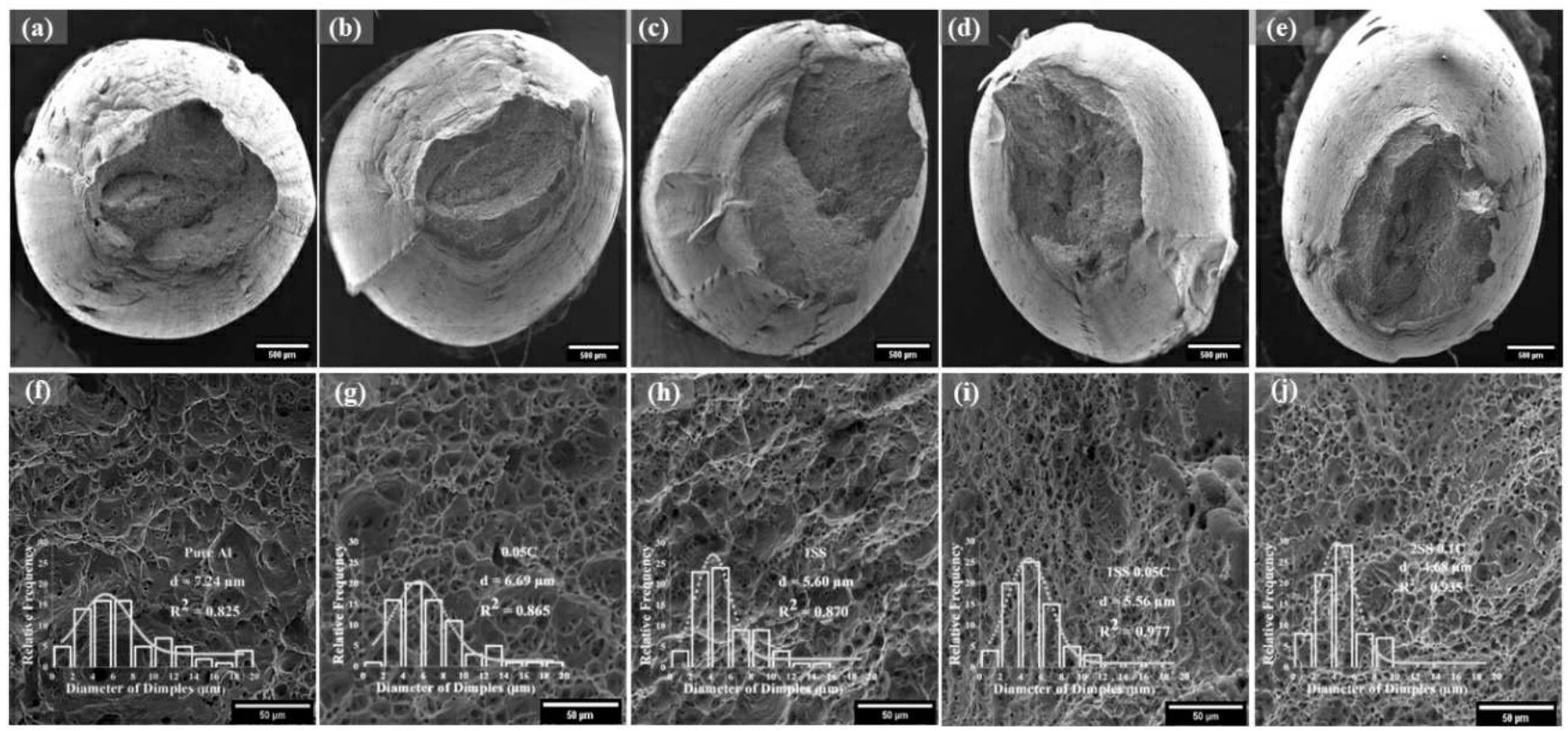

Figure 6. (a) Al-EC, (b) 0.05 wt.\% MWCNT, (c) 1 wt. $\%$ SS powder, (d) 1 wt.\% SS powder- 0.05 wt.\% MWCNT, (e) 2 wt. $\%$ SS powder-0.1 wt.\% MWCNT.

lingot $^{38}$. The addition of $1 \%$ of SS particles significantly refines the grains by addition of the alloy elements ${ }^{38}$. The addition of $0.05 \mathrm{wt} . \% \mathrm{CNTs}$ refines them even more, due to the high heat transfer from the CNT insertion, while the $2 \mathrm{wt} . \%$ SS and $0.1 \mathrm{wt} . \%$ CNT exceed the limit of absorption of the aluminum in this temperature, deriving from a growth of the grains and from lower mechanical, microstructural, and electrical properties ${ }^{17,30}$.

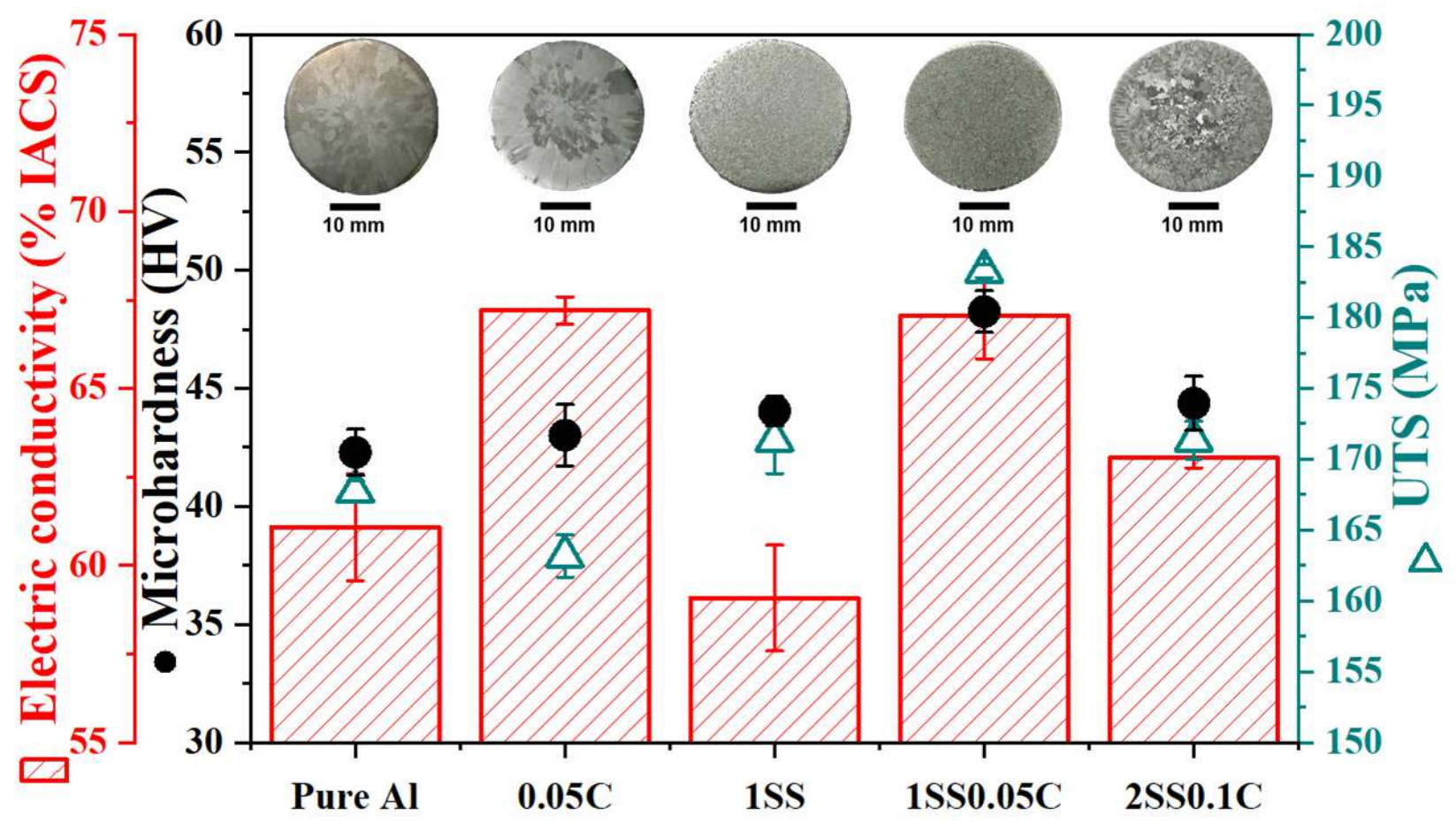

Figure 7. Microhardness, electric conductivity, UTS, and macrographs. 


\section{Conclusions}

This work showed a novel process in manufacturing a nanocomposite aluminum alloy with higher mechanical properties and electric conductive. The best aluminum alloy was the combination of $1 \mathrm{wt} . \%$ of stainless-steel particles and $0.05 \mathrm{wt} . \%$ of MWCNT, demonstrating 10\% of increment in all of its properties. The mechanical performance is due to the SS powder and the electric conductive to the CNT. The bond between the SS powder matrix and the MWCNT, which comes from the chemical treatment applied, is fundamental to incorporate succesfully incorporate the nanoparticles in the aluminum matrix. The stress-strain curve of the $1 \mathrm{SS} 0.05 \mathrm{C}$ alloy had the best results for tensile strength, toughness and deformation, than the other alloys tested. With $1 \%$ in weight of powdered SS particles and without the CNT, the UTS increases slightly, due to residual stresses arising from the alloying elements to the matrix, reducing strain and electrical conductivity ( $5 \%$ ). The $1 \mathrm{SS} 0.05 \mathrm{C}$ sample had a better behavior in all its properties (UTS, deformation, tenacity, microhardness and EC), an almost 10\% increase in each one. This showed the effect of nanotubes with the SS powder, maintaining its reinforcing effect by effectively bonding within the aluminum matrix.

\section{Experimental Procedure}

Alloys elements preparation. MWCNT with $95.7 \%$ purity and $304 \mathrm{~L}$ stainless-steel particles sifted until $44 \pm 5 \mu \mathrm{m}$ were the alloy elements. MWCNT was the chemical treatment (CT) with Hydrogen Peroxide, inserted together with the SS 304L powder in an ultrasonic bath $(55 \mathrm{kHz}, 120 \mathrm{~W})$, with isopropyl alcohol for $10 \mathrm{~min}$; afterwards, the mixture was dried at 130 ${ }^{\circ} \mathrm{C}$ to evaporate the $\mathrm{H}_{2} \mathrm{O}_{2}$ and the isopropyl alcohol ${ }^{10,11,14,39,40}$. The crystalline, doping, and amorphous carbon degree of the CNT used a Raman spectroscopy Jovin Ivon. An equipment Bruker, model 8 Advance with Bragg-Brentane geometry, Lyns Eye detector, $\mathrm{Cu}$ tube, $\mathrm{K} \alpha 1=1.541$ and Ni filter $\mathrm{K} \beta$ performed the X-ray diffraction (XRD) analyses. Micrographs of the nanostructured powder were obtained using a Scanning Electron Microscope (SEM), being displayed in the Supplementary Fig. S8 online. TEM micrographs indicated the as-received CNT and the chemical treatment.

Casting procedure. Aluminum was melted to $900^{\circ} \mathrm{C}$ for four hours. The operational system adopted for the solidification process was the mold in a cylindrical metallic keel consisting of a hollow steel cylinder to obtain a final product of $150 \mathrm{~mm}$ length $\mathrm{x} 25 \mathrm{~mm}$ diameter. MWCNT chemical treatment was added to $780^{\circ} \mathrm{C}$, measured with a thermocouple, mixed in an inert atmosphere of pure Argon, rate of $0.2 \mathrm{l} / \mathrm{s}$. In $720^{\circ} \mathrm{C}$, The mixing process was interrupted, depositing the metal liquid in the mold. Figure 1 shows the solidification modes of the three mains alloys, displaying the behavior of each alloy element when only carbon nanotubes, and the nanostructured powder in minor (1SS0.05C) and major amount (2SS0.1C) were added. Five alloys were prepared, $\mathrm{Al}_{E C}$ as reference, and four with different content of alloy elements, with $0.05 \mathrm{wt} . \% \mathrm{CNT}(0.05 \mathrm{C}), 1$ wt.\% SS (1SS), 1 wt.\%SS-0.05 wt.\% CNT (1SS0.05C), and 2 wt.\%SS-0.1 wt.\% CNT (2SS0.1C).

Wire Characterization. A multiohmmeter (Megabrás, MPK-2000 model) evaluated the electric conductive of the wires of $3 \mathrm{~mm}$, obtained after a lamination process; over standard ASTM B193-1941. Tensile strength tests were made with a servo pulser Kratos, IKCL1 model, using the standard, ASTM E8/E8M-16a ${ }^{42}$, with three samples to each alloy. Failure area was analyzed with a SEM. A Mitutoyo equipment performed the microhardness Vickers test, with a $3 \mathrm{~N}$ load, over the standard ASTM E384 - 11. The micrographs and failure analyses utilized a Scanning Electron Microscope (SEM), voltage of $20 \mathrm{kV}$, with Energy-dispersive X-ray spectroscopy (EDS) for mapping the alloys elements.

\section{References}

1. Jagannatham, M. et al. Tensile properties of carbon nanotubes reinforced aluminum matrix composites: A review. Carbon 160, 14-44 (2020).

2. Tjong, S. C. Recent progress in the development and properties of novel metal matrix nanocomposites reinforced with carbon nanotubes and graphene nanosheets. Mater. Sci. Eng. R: Reports 74, 281-350 (2013).

3. Thostenson, E. T., Li, C. \& Chou, T.-W. Nanocomposites in context. Compos. science technology 65, 491-516 (2005).

4. Suarez, S., Lasserre, F. \& Mücklich, F. Mechanical properties of mwnt/ni bulk composites: Influence of the microstructural refinement on the hardness. Mater. Sci. Eng. A 587, 381-386 (2013).

5. Suarez, S., Rosenkranz, A., Gachot, C. \& Mücklich, F. Enhanced tribological properties of mwcnt/ni bulk compositesinfluence of processing on friction and wear behaviour. Carbon 66, 164-171 (2014).

6. Cha, S. I., Kim, K. T., Arshad, S. N., Mo, C. B. \& Hong, S. H. Extraordinary strengthening effect of carbon nanotubes in metal-matrix nanocomposites processed by molecular-level mixing. Adv. Mater. 17, 1377-1381 (2005).

7. Loayza, C. R. et al. Incorporation of aws 3161 wire nanostructured with nickel-carbon nanotube by arc welding. J. Compos. Mater. 52, 1899-1906 (2018). 
8. dos Reis, M. A. L. et al. Raman spectroscopy fingerprint of stainless steel-mwcnts nanocomposite processed by ball-milling. AIP Adv. 8, 015323 (2018).

9. Borges, D. J. et al. A new approach for the reinforcement of ss 3041 via arc welding: using nanostructured flux cored electrode. Diam. Relat. Mater. 92, 138-145 (2019).

10. Borges, D. et al. Stainless steel weld metal enhanced with carbon nanotubes. Sci. reports 10, 1-13 (2020).

11. Simões, S., Viana, F., Reis, M. A. \& Vieira, M. F. Improved dispersion of carbon nanotubes in aluminum nanocomposites. Compos. structures 108, 992-1000 (2014).

12. Rodrigues, F. A. d. S. et al. Electrical and tensile properties of carbon nanotubes-reinforced aluminum alloy 6101 wire. $J$. Nanosci. Nanotechnol. 17, 4837-4841 (2017).

13. Araujo, P. et al. Multiwall carbon nanotubes filled with al4c3: Spectroscopic signatures for electron-phonon coupling due to doping process. Carbon 124, 348-356, DOI: https://doi.org/10.1016/j.carbon.2017.08.041 (2017).

14. Simões, S., Viana, F., Reis, M. A. \& Vieira, M. F. Microstructural characterization of aluminum-carbon nanotube nanocomposites produced using different dispersion methods. Microsc. Microanal. 22, 725-732 (2016).

15. Ajayan, P. M. \& Tour, J. M. Nanotube composites. Nature 447, 1066-1068 (2007).

16. Lin, D., Saei, M., Suslov, S., Jin, S. \& Cheng, G. J. Super-strengthening and stabilizing with carbon nanotube harnessed high density nanotwins in metals by shock loading. Sci. reports 5, 1-11, DOI: https://doi.org/10.1038/srep15405 (2015).

17. Hanizam, H., Salleh, M. S., Omar, M. Z. \& Sulong, A. B. Optimisation of mechanical stir casting parameters for fabrication of carbon nanotubes-aluminium alloy composite through taguchi method. J. Mater. Res. Technol. 8, 2223-2231 (2019).

18. Esawi, A. \& Morsi, K. Dispersion of carbon nanotubes (cnts) in aluminum powder. Compos. Part A: Appl. Sci. Manuf. 38, 646-650 (2007).

19. Bakshi, S. R., Lahiri, D. \& Agarwal, A. Carbon nanotube reinforced metal matrix composites-a review. Int. materials reviews 55, 41-64 (2010).

20. Bakshi, S. R. et al. Spark plasma sintered tantalum carbide-carbon nanotube composite: Effect of pressure, carbon nanotube length and dispersion technique on microstructure and mechanical properties. Mater. Sci. Eng. A 528, 2538-2547 (2011).

21. Nieto, A., Agarwal, A., Lahiri, D., Bisht, A. \& Bakshi, S. R. Carbon Nanotubes: Reinforced Metal Matrix Composites (CRC Press, 2021).

22. Chen, B. et al. An approach for homogeneous carbon nanotube dispersion in al matrix composites. Mater. \& Des. 72, 1-8 (2015).

23. Zhang, J. et al. Carbon science in 2016: Status, challenges and perspectives. Carbon 98, 708-732 (2016).

24. Peng, Y. \& Liu, H. Effects of oxidation by hydrogen peroxide on the structures of multiwalled carbon nanotubes. Ind. \& Eng. Chem. Res. 45, 6483-6488 (2006).

25. Zeng, X. et al. A new technique for dispersion of carbon nanotube in a metal melt. Mater. Sci. Eng. A 527, 5335-5340 (2010).

26. dos Reis, M. A. L. et al. One-step synthesis and characterization of a nanocomposite based on carbon nanotubes/aluminum and its reinforcement effect on the metal matrix. (2015).

27. Samuel Ratna Kumar, P., Robinson Smart, D. \& John Alexis, S. Corrosion behaviour of aluminium metal matrix reinforced with multi-wall carbon nanotube. J. Asian Ceram. Soc. 5, 71-75 (2017).

28. Akbari, M. K., Baharvandi, H. \& Shirvanimoghaddam, K. Tensile and fracture behavior of nano/micro tib2 particle reinforced casting a356 aluminum alloy composites. Mater. \& Des. (1980-2015) 66, 150-161 (2015).

29. Ramanathan, A., Krishnan, P. K. \& Muraliraja, R. A review on the production of metal matrix composites through stir casting-furnace design, properties, challenges, and research opportunities. J. Manuf. processes 42, 213-245 (2019).

30. Kuz'Min, M., Kuz'mina, M. Y. \& Kuz'Mina, A. Production and properties of aluminum-based composites modified with carbon nanotubes. Mater. Today: Proc. 19, 1826-1830 (2019).

31. Housaer, F. et al. Interfacial characterization in carbon nanotube reinforced aluminum matrix composites. Mater. Charact. 110, 94-101 (2015).

32. Rashad, M., Pan, F., Tang, A. \& Asif, M. Effect of graphene nanoplatelets addition on mechanical properties of pure aluminum using a semi-powder method. Prog. Nat. Sci. Mater. Int. 24, 101-108 (2014). 
33. Hou, J. et al. Origin of abnormal strength-electrical conductivity relation for an al-fe alloy wire. Materialia 7, 100403 (2019).

34. Liu, Z., Xiao, B., Wang, W. \& Ma, Z. Tensile strength and electrical conductivity of carbon nanotube reinforced aluminum matrix composites fabricated by powder metallurgy combined with friction stir processing. J. Mater. Sci. \& Technol. 30, 649-655 (2014).

35. Narayanasamy, R., Parthasarathi, N., Ravindran, R. \& Narayanan, C. S. Analysis of fracture limit curves and void coalescence in high strength interstitial free steel sheets formed under different stress conditions. J. materials science $\mathbf{4 3}$, 3351-3363 (2008).

36. Derpeński, $€$. Ductile fracture behavior of notched aluminum alloy specimens under complex non-proportional load. Materials 12, 1598 (2019).

37. Karabay, S. Modification of aa-6201 alloy for manufacturing of high conductivity and extra high conductivity wires with property of high tensile stress after artificial aging heat treatment for all-aluminium alloy conductors. Mater. \& design 27, 821-832 (2006).

38. Zhang, Y., Ma, N., Yi, H., Li, S. \& Wang, H. Effect of fe on grain refinement of commercial purity aluminum. Mater. \& design 27, 794-798 (2006).

39. Simões, S., Viana, F., Reis, M. A. \& Vieira, M. F. Effect of dispersion method in the production of al-cnts nanocomposites. Microsc. Microanal. 22, 52-53 (2016).

40. Behler, K., Osswald, S., Ye, H., Dimovski, S. \& Gogotsi, Y. Effect of thermal treatment on the structure of multi-walled carbon nanotubes. J. Nanoparticle Res. 8, 615-625 (2006).

41. Fazio, M. G. et al. Standard test method for resistivity of electrical conductor materials. ASTM: B193-89 2 (1990).

42. Standard, A. E8/e8m-11. Standard test methods for tension testing metallic materials, ASTM book standards (2011).

\section{Acknowledgements}

All authors are grateful to agencies for financial support, for the work teams of the Materials Engineering Research Group (GPEMAT) and the Material Characterization Laboratory (LCAM) of the Federal University of Pará (UFPA), where all the experimental tests were performed, and special thanks to the Engineering of Natural Resources of the Amazon Graduate Program (PRODERNA) and National Council for Scientific and Technological Development (CNPq) which provided the C.L. scholarships, Number 166397/2017-2 and Number 170412/2017-2. The authors would like to thank the LABNANO/CBPF for technical support during electron microscopy work. The authors thank PROPESP/UFPA for the financial support regarding the publication costs of this paper.

\section{Author contributions statement}

E.P. and C.L. performed the experiments, were responsible for most of the analysis contained in the paper, which was written by E.P., with contributions from C.L. e V.R. and reviewed by all authors. The laboratories in which most experiments took place were supervised by E.B., J.Q. and J.S. In addition, V.M. and V.R. helped with the casting and solidification procedures and the electrical conductivity tests. M.R. assisted in both XRD and Raman analysis.

\section{Competing interests}

Te authors declare no competing interests.

\section{Additional information}

Supplementary information Nanostructured Powder Characterization 


\begin{tabular}{|l|l|l|l|l|l|l|l|l|}
\hline MWCNT & \multicolumn{1}{l|}{} \\
\hline Parameters & $\mathrm{D}_{l}$ & $\mathrm{D}_{r}$ & $\mathrm{D}_{L O}$ & $\mathrm{D}_{\text {middle }}$ & $\mathrm{G}_{B W F}$ & $\mathrm{G}_{\text {inner }}$ & $\mathrm{G}_{\text {outer }}$ & $\mathrm{D}^{\prime}$ \\
\hline $\mathrm{X}_{0}$ & 1317.8 & 1345 & 1371.7 & 1482.8 & 1566.6 & 1583.3 & 1606.9 & 1623.7 \\
\hline FWHM & 34.2 & 38.5 & 46.9 & 36.1 & 41.5 & 30.2 & 23.7 & 22.3 \\
\hline $\mathrm{A}$ & 2194.7 & 13667.3 & 3885.5 & 1052.6 & 6487.7 & 9549.9 & 3350.7 & 1108.3 \\
\hline $\mathrm{H}$ & 43.4 & 239.5 & 56.1 & 19.3 & 104.2 & 208.6 & 92.5 & 32.6 \\
\hline
\end{tabular}

Table S1. Summary of the center $\left(\mathrm{X}_{0}\right)$, full width at half maximum (FWHM), area (A), and height $(\mathrm{H})$.

\begin{tabular}{|c|c|c|c|c|c|c|c|c|}
\hline \multicolumn{9}{|c|}{ 304LSS-CNT } \\
\hline Parameters & $\mathrm{D}_{l}$ & $\mathrm{D}_{r}$ & $\mathrm{D}_{L O}$ & $\mathrm{D}_{\text {middle }}$ & $\mathrm{G}_{B W F}$ & $\mathrm{G}_{\text {inner }}$ & $\mathrm{G}_{\text {outer }}$ & $\mathrm{D}^{\prime}$ \\
\hline $\mathrm{X}_{0}$ & 1325.7 & 1348.4 & 1369.4 & 1467.1 & 1551.6 & 1571.6 & 1584.8 & 1612.5 \\
\hline FWHM & 24.9 & 34.8 & 39.1 & 55.5 & 44.9 & 28.6 & 27.2 & 24.8 \\
\hline A & 1861.4 & 16968.3 & 5517.7 & 1161.4 & 3869.8 & 14055.4 & 13472.5 & 6170.4 \\
\hline $\mathrm{H}$ & 47.6 & 310.1 & 89.9 & 13.3 & 54.9 & 312.8 & 315.4 & 158.1 \\
\hline
\end{tabular}

Table S2. Summary of the center $\left(\mathrm{X}_{0}\right)$, full width at half maximum (FWHM), area (A), and height $(\mathrm{H})$.
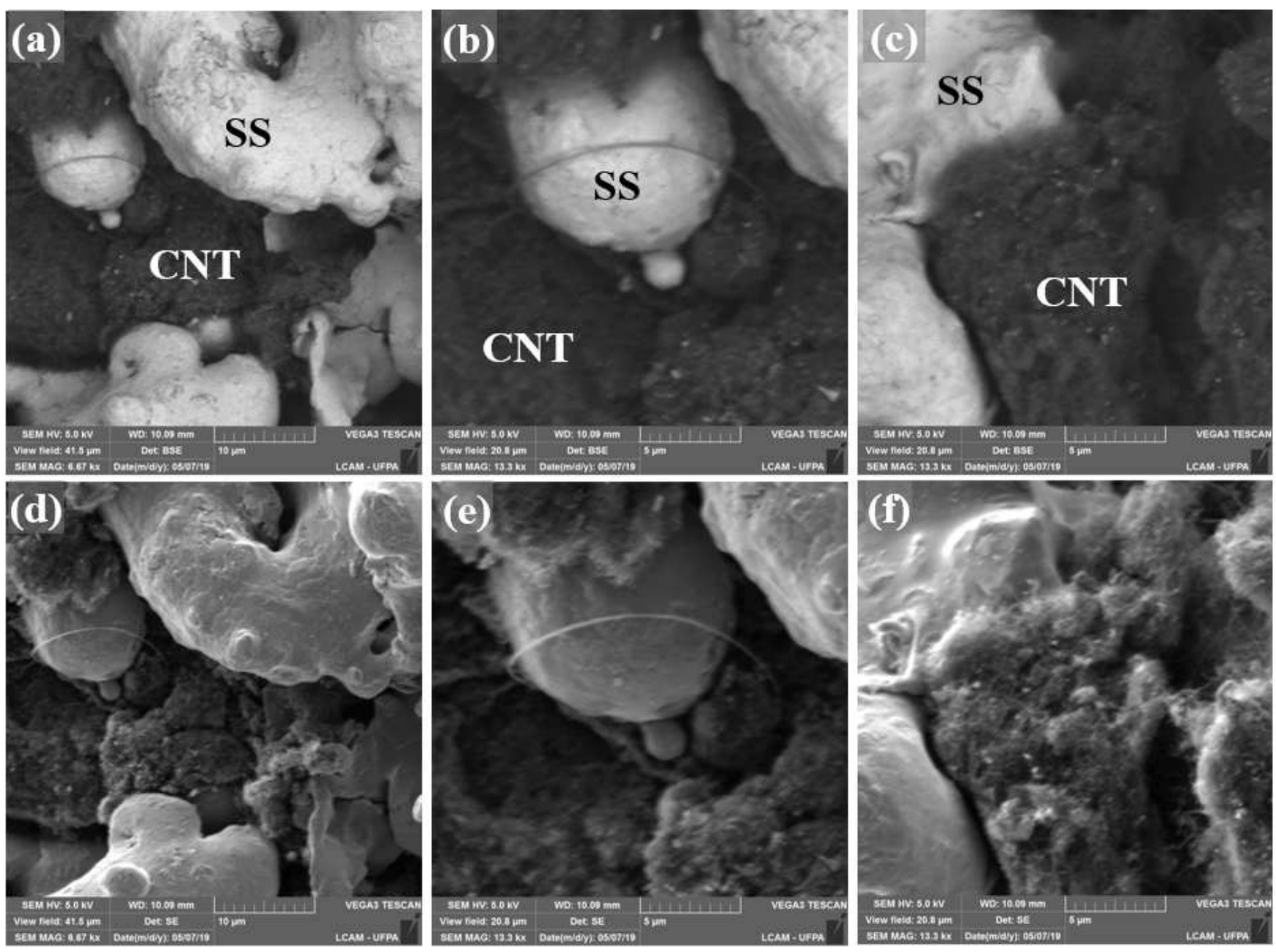

Figure S8. SEM micrographs indicating the nanostructured powder using BSE mode (a, b, c) and SE mode (d, e, f). 


\begin{tabular}{|l|l|l|}
\hline Parameters & MWCNT & 304LSS-CNT \\
\hline $\mathrm{ACD}$ & $8 \%$ & $4 \%$ \\
\hline $\mathrm{I}_{D} / \mathrm{I}_{G}$ & 0.95 & 0.66 \\
\hline $\mathrm{I}_{D} / \mathrm{I}_{\text {Ginner }}$ & 1.1 & 0.99 \\
\hline $\mathrm{I}_{D} / \mathrm{I}_{\text {Gouter }}$ & 2.6 & 0.98 \\
\hline
\end{tabular}

Table S3. Amorphous Carbon Degree (ACD), $\mathrm{I}_{D} / \mathrm{I}_{G}, \mathrm{I}_{D} / \mathrm{I}_{\text {Ginner }}$, and $\mathrm{I}_{D} / \mathrm{I}_{\text {Gouter }}$ rates for the MWCNT and the nanostructured powder 304LSS-NTC.
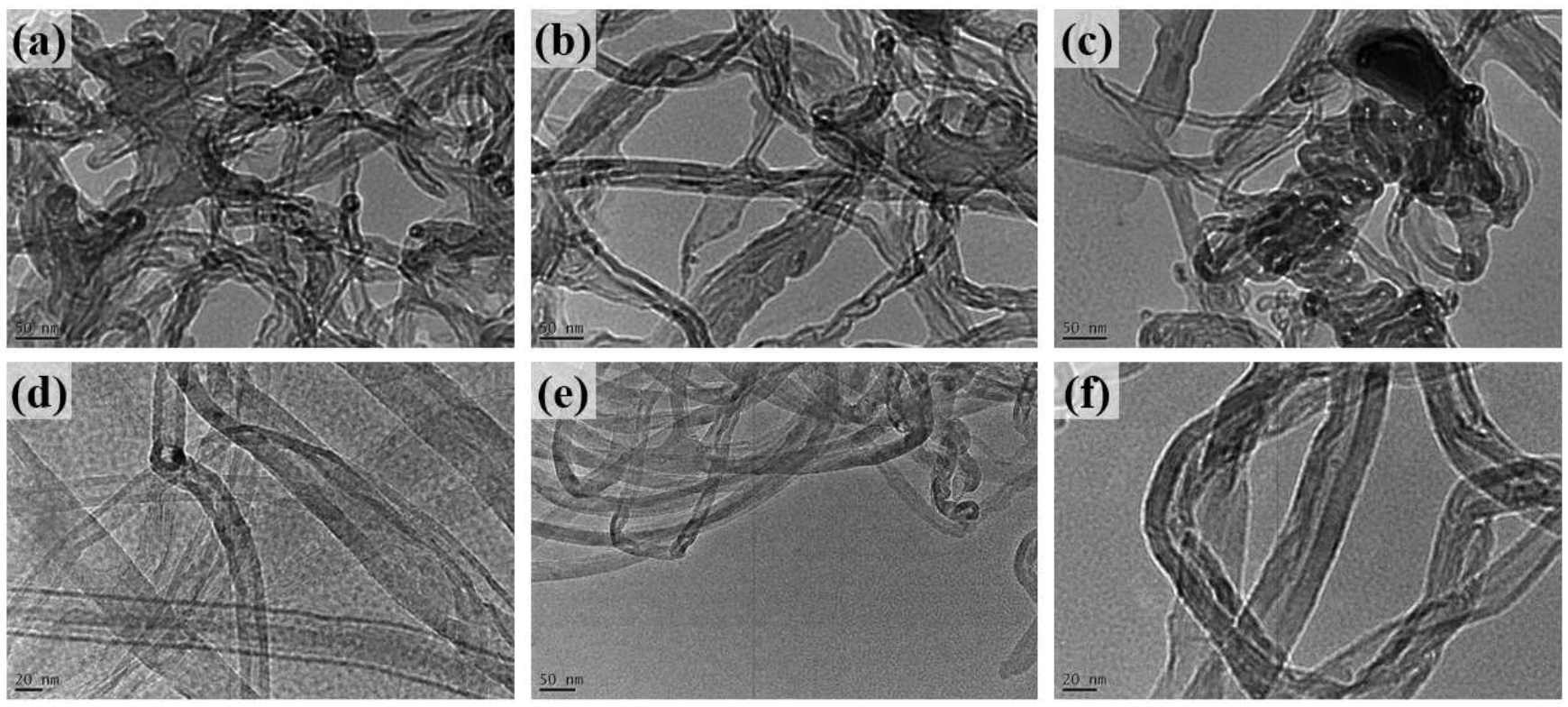

Figure S9. TEM micrographs exhibited as-received $\operatorname{MWCNT}(a, b, c)$ and chemical treated (d, e, f). 